\title{
The Acceptance of Moodle: An Empirical Study Based on UTAUT
}

\author{
Hsiao-Hui Hsu \\ Department of Applied Foreign Languages, Lunghwa University of Science and Technology, Taoyuan \\ Email: stella6637@yahoo.com.tw
}

Received 2012

\begin{abstract}
This study aimed to investigate students' acceptance and use of Moodle employing the model of Unified Theory of Acceptance and Use of Technology (UTAUT) and further understand the four constructs of the model. Data, collected from 47 university students' questionnaire survey, revealed that performance expectancy, effort expectancy, and social influence were the major three keys of the UTAUT model to assess the acceptance of Moodle. Behavioral intention acted as a mediator to urge students to involve in the use of Moodle.
\end{abstract}

Keywords: Moodle; UTAUT; Computer-Mediated Communication (CMC)

\section{Introduction}

With the increasing pervasive use of computer support collaborative learning (CSCL), CSCL environment has provided a supplementary medium for interactions to take place in the traditional face-to-face classroom. Computer-mediated communication (CMC), one of the most common functions of CSCL, has been widely employed and numerous CMC projects were initiated and documented (Warschauer, 1997; Warschauer \& Meskill, 2000). CMC is defined as any form of data exchange across two or more networked computers or communication that occurs via computer-mediated formats between two or more individuals. Popular forms of CMC include e-mail, video, audio or text chat, bulletin boards, weblogs (blogs), the wiki, etc. After years of observations and studies, researchers found that CMC tasks indeed motivate students to participate in communication as well as in language learning.

Of the CMC forms, online discussion forums are excellent means in learning for several reasons. First, they are flexible and easy to be created. Second, discussions are extended communication and interaction dealing with some particular topics. So, learners have to solve the challenge of communication and information, which offers learners opportunities for engaging in communicative practice in the target language. Third, apart from the language itself, discussions also increase learners' sensitivity to certain points of view and alternative explanations that can help construct world knowledge. Fourth, the contents of online discussions can be recorded, threaded, and retrieved anytime anywhere so that learners can read them and the instructor can probe students' learning via the web. Last but not least, online discussion forums establish a safe atmosphere which may encourage students to participate in discussions and express themselves. Moodle, a well-known Course Management System (CMS) or LMS, allows such interaction to take place among learners and further provides a platform that leads learners to knowledge and information sharing. The objectives of this study are to understand user's acceptance of Moodle, and to examine the relationship among the four constructs in the UTAUT model.

\section{Theoretical Framework}

\section{Computer-Mediated Communication (CMC)}

These years have witnessed the development of Internet technology to meet different purposes of communication. The emergence of the latest means, computer-mediated communication, has provided users many opportunities for exploration, reflection, and articulation. Invented and implemented by Turoff in 1970s, CMC is considered "a collective intelligence environment, which would use the computer to structure human communication for information exchange and effective problem solving” (Harasim, 1990, p. 41). Harasim (1989) further characterized $\mathrm{CMC}$ as independent of time and place and many-tomany communication. With the use of CMC, traditional faceto-face courses can be transformed to a highly interactive way of teaching and learning (Vrasidas \& McIssac, 1999; Zeng \& Takatsuka, 2009). Hence, CMC is found to be a viable means of teaching and learning.

Computer-mediated communication can either be synchronous (SCMC), happening in real time or asynchronous (ASCMC) according to its temporal structure (Jones, 1995). The nature of synchronicity of CMC increases the level of cognition through immediacy and control of interaction. The asynchronicity of $\mathrm{CMC}$, on the other hand, increases the interactivity through ample wait-time of the response. Computer-mediated communication has several advantages. It can promote structured learning, provide learners with more efficient access to online resources, and facilitate interaction with peers and instructors. These strengths make communicative practice via CMC outside the classrooms possible.

\section{The UTAUT Model}

The Technology Acceptance Model (TAM) was one of the robust and influential models used in organizations to explain the adoption behavior of information technology (Szajna, 1996). It claimed that perceived usefulness and ease-of-use would lead to positive outcomes. Based on TAM, Venkatesh, Morris, Davis, and Davis (2003) developed the Unified Theory of Accep- 
tance and Use of Technology (UTAUT) model to comprehensively predict individual acceptance of information technology, i.e. intention and behavior. In the UTAUT model, four key constructs are emphasized: performance expectancy refers to the usefulness of the tool; effort expectancy means the easeof-use of the tool; social influence indicates the influence of social members such as teachers and students; and the construct of facilitating conditions is about the technological support. According to Venkatesh et al. (2003), if the values of the four constructs are higher, the value of behavioral intention to use the tool is higher, and so is students' acceptance of the technology. In other words, students' behavioral intention determines their acceptance of technology. However, Wu and Chen (2006) claimed that facilitating conditions do not influence EFL college students' behavioral intention.

In addition, although the model of UTAUT provides feasible ways to understand technology acceptance, most of the previous studies focused mainly on large organizations or higher education or highlighted the roles of age, gender, and experience (Marchewka, Liu, \& Kostiwa, 2007). So far scant attention has been paid to the follow-up step such as the frequency of use and time involvement related to Moodle. Thus, it needs to be tested whether the UTAUT model subsists in the EFL environment and whether behavioral intention acts as a mediator to motivate students to be more active in the use of Moodle.

\section{Learning Management System: Moodle}

Moodle, a well-known Course Management System (CMS) or LMS, is an open source that gives teachers to create their dynamic, effective online learning sites for students. Moodle, in fact, has become very popular among educators around the world nowadays because of its easiness and economy. According to Ellis (2009), a robust LMS should contain several functions such as automate administration, self-service and selfguided services, rapid assembly and delivery of learning content, a scalable web-based platform, portability and standard support, and knowledge reuse. Moodle has these. Moodle offers these advanced and user-friendly functions for encouraging the collaborative work of students and teachers. It facilitates and enhances the proven teaching principles that the traditional classroom has. More than that, Moodle allows hundreds of students to engage in, no matter whom they are or where they are. Many institutions use it as their platform to conduct fully online courses and plan to replace Blackboard or WebCT with it. Moodle provides students with in-depth, rich interactive experiences. Moodle has revolutionized the learning process.

\section{Methodology}

\section{Subjects}

The subject pool consisted of 47 EFL university sophomore students in Taipei, Taiwan. They took 6 hours of English reading, listening and speaking, and conversation per week.

\section{Materials}

An online discussion forum was set up on Moodle platform. An UTAUT questionnaire with 5-point Likert Scale was adopted in this study. The questionnaire contained 20 questions in four constructs, users' intention, and behavior (i.e. frequency and time). The contents were performance expectancy (e.g. I think Moodle is useful for my learning), effort expectancy (e.g. I think it is easy to use Moodle), social influence (e.g. Teachers support me to use Moodle), facilitating conditions (e.g. I know how to use Moodle), intention (e.g. I have an intention to use Moodle), and behavior (e.g. how many times and how many hours per week students spent on Moodle). Three open-ended questions were investigated as well, namely whether the students have received computer literacy training; if yes, how long; whether they had any experience in using Moodle; and how the students felt about Moodle. The instructor was interviewed as well.

\section{Statistics Analysis}

Two statistic analyses were conducted in the study: correlation and regression analyses. The former was used to examine the relationship among the variables, i.e. those in the UTAUT model in the EFL environment, whereas the latter were employed to examine the mediating effect of behavioral intention. The validation of UTAUT in a longitudinal study accounted for 70\% (Venkatesh \& Davis, 2000). The reliability of the six variables in the study was acceptable; their values of Cronbach's Alpha ranged from 0.88 to 0.69 .

\section{Results}

The following results present whether the variables of the UTAUT model predict students' acceptance of Moodle and what the relationship among the variables in the model is. Table 1 showed that except the variable of facilitating conditions, the other variables were significantly positively interrelated.

In Table 2, the results of Model 1, 2, 3 were significant $(p<.05)$; however, when the four constructs and the behavioral intention were lumped together to predict time involvement in Model $4\left(\mathrm{R}^{2}=.252, \mathrm{~F}=6.395, \mathrm{p}<.001\right)$, the influence of the four constructs either disappeared or decreased, but behavioral intention was still significantly influential. Table 3 showed the similar results as those in Table 2.

Table 1.

Correlations among the Variables.

\begin{tabular}{|l|c|c|c|c|c|c|c|}
\hline & Perform & Effort & Social & Facilita & Behav & Frequency & Time \\
\hline Perform & 1 & & & & & & \\
\hline Effort & $.258^{* *}$ & 1 & & & & & \\
\hline Social & $.275^{* *}$ & $.277^{* *}$ & 1 & & & & \\
\hline Facilitating & .018 & .029 & -.086 & 1 & & & \\
\hline Behavior & $.536^{* *}$ & $.465 * *$ & $.373 * *$ & -.053 & 1 & & \\
\hline Frequency & $.506^{* *}$ & $.386^{* *}$ & $.485^{* *}$ & -.112 & $.516^{* *}$ & 1 & \\
\hline Time & $.316^{* *}$ & .062 & $.365^{* *}$ & -.006 & $.529^{* *}$ & $.529^{* *}$ & 1 \\
\hline
\end{tabular}

Note: 1. Perform: performance expectancy, Effort effort expectancy; Social: social influence; Facilitating: facilitating conditions, Behatior: behavioral intention; Frequency. frequency of the use of Moodle; Time: time involvement in Moodle. $2 .{ }^{* *} p<.001$

Table 2.

The Mediator of Behavioral Intention to Predict Time Involvement.

\begin{tabular}{|l|c|c|c|c|}
\hline \multirow{2}{*}{} & Behavioral intention & \multicolumn{3}{|c|}{ Time involvement } \\
\cline { 2 - 5 } & Model 1 & Model 2 & Model 3 & Model 4 \\
\hline Perform & $.410^{* * *}$ & $.250^{*}$ & & .118 \\
\hline Effort & $.314^{* * *}$ & -.094 & & -.195 \\
\hline Social & $.169^{* *}$ & $.325^{* *}$ & & $.270^{*}$ \\
\hline Facilitating &. .055 & -.032 & & .049 \\
\hline Behavior & $.474^{* * *}$ & & $.394^{* * *}$ & $.324^{*}$ \\
\hline $\mathrm{R}^{2}$ & .431 & .192 & .156 & .252 \\
\hline F-value & $18.189^{* * * *}$ & $5.710^{* * * *}$ & $18.232^{* * *}$ & $6.395^{* * *}$ \\
\hline
\end{tabular}


Table 3.

The Mediator of Behavioral Intention to Predict Frequency of Use.

\begin{tabular}{|c|l|l|l|l|}
\hline \multirow{2}{*}{} & \multicolumn{1}{|c|}{ Behavioral intention } & \multicolumn{3}{|c|}{ Frequency of use } \\
\cline { 2 - 5 } & \multicolumn{1}{|c|}{ Model 1 } & Model 2 & Model 3 & Model 4 \\
\hline Perform & $.410^{* * *}$ & $.367^{* * *}$ & & $.295 * *$ \\
\hline Effort & $.314^{* * *}$ & $.206^{* *}$ & & .151 \\
\hline Social & $.169^{*}$ & $.319^{* * *}$ & & $.289^{* *}$ \\
\hline Facilitating & -.055 & .097 & & -.087 \\
\hline Behavior & $.474^{* * *}$ & & $.516^{* * *}$ & .175 \\
\hline $\mathrm{R}^{2}$ & .431 & .430 & .266 & .448 \\
\hline F-value & $18.189 * * *$ & $18.122^{* * *}$ & $35.842^{* * *}$ & $15.394^{* * *}$ \\
\hline
\end{tabular}

\section{Discussion and Implications}

This study employed the UTAUT model to assess students' acceptance and use of Moodle and further clarified the relationship among the variables of the model. Several findings are revealed. First of all, when three out of the four constructs of the UTAUT model (i.e. performance expectancy; effort expectancy, and social influence) are significantly related to the students' behavioral intention as well as their time involvement and frequency of use, it signifies that students' belief in usefulness and easiness and their encouragement from social members decide their acceptance of the technological tool. This is different from the theory of Venkatesh et al. (2003), but similar to Wu \& Chen's (2006). We claim that the construct of facilitating conditions is not a salient predicator of technology acceptance in the advanced information infrastructure community, like Taiwan. However, the criteria of advanced information infrastructure need to be clarified; meanwhile, more subjects can be employed in the following studies.

As to the use of Moodle, some implications are addressed in the following. In accordance with the viewpoint of Šumak et al. (2010), social influence is significant determinant of students' behavioral intention. Students' behavioral intentions were shown to be significant determinant of actual use of Moodle. Hence, Moodle acts as a successful supplementary platform for language learners. The results of the open-ended questions showed that $98 \%$ of the students agreed that Moodle was useful to learn English. Eighty-four percent of them had had the experiences in using Moodle in the past two years. Moreover, Moodle brings the close relationship between teachers and classmates. Sharing and openness feature Moodle, which offers students a productive and collaborative environment. The instructor, on the other hand, holds positive attitude towards using Moodle as well. Moodle expands the time and the place of instruction with less cost because students can interact with each other independent of time and place constraint. Most of all, Moodle contains historical record of the students' interaction process. "It definitely is a good idea to use Moodle" one instructor said, "I do not have subsidies or technical support, but I still survived." "Obviously, familiarity and friendliness play an important role in the success of information technology.

\section{Conclusions}

In the online discussion forum, students can get rid of their anxiety because they neither have to face the pressure of speaking to their peers in person nor give timely responses to other participants. Additionally, they do not feel embarrassed for their poor English because the interface of Moodle can be open only to the specific participants whom they may be already familiar with. This can further facilitate students' autonomy in participating in communicative activities and in learning the target language, i.e. English. Learning a foreign language is a long, tough journey which needs learners' involvement in terms of time and efforts. Without ample practice, high motivation and autonomy, it is impossible to achieve their communicative competence. To create more efficient learning environments, it is believed that multimedia tools like the online discussion forum in the Moodle interface can be considered a significant choice for the $21^{\text {st }}$ century and the years to come.

\section{Acknowledgements}

This study is partially sponsored by the National Science Council of Taiwan under Grant NSC 101-2410-H-262-001. The authors would like to thank all the students who participated in and contributed to this study.

\section{REFERENCES}

Ellis, Ryann K. (2009). Field Guide to Learning Management Systems. ASTD Learning Circuits. URL (last checked 10 April 2012) http://www.astd.org/NR/rdonlyres/12ECDB99-3B91-403E-9B15-7E 597444645D/23395/LMS_fieldguide_20091.pdf

Harasim, L. M. (1989). Online education: A new domain. In R. Mason \& A. Kaye (Eds.), Mindweave: Communication, computers and distance education (pp. 50-62). New York: Pergamon Press.

Harasim, L. M. (1990). Online education: An environment for collaboration and intellectual amplification. In L. M. Harasim (Ed.), Online education: Perspectives on a new environment (pp. 39-66). New York: Praeger Publishers.

Jones, S. G. (Ed.) (1995). CyberSociety: Computer-Mediated communication and community. Sage.

Marchewka, J. T., Liu, C., \& Kostiwa, K. (2007). An Application of the UTAUT Model. Communications of the IIMA, 94(7), 93-104.

Šumak, B., Polancic, G., \& Hericko, M. (2010). An Empirical Study of Virtual Learning Environment Adoption Using UTAUT. Paper presented at the 2010 Second International Conference on Mobile, Hybrid, and On-Line Learning.

Szajna, B. (1996). Empirical evaluation of the revised Technology Acceptance Model, Management Science, 42(1), 85-92.

Venkatesh, V., \& Davis, F. D. (2000). A theoretical extension of the technology acceptance model: Four longitudinal studies. Management Science, 46(2), 186-204.

Venkatesh, V., Morris, M.G., Davis, G. B., \& Davis, F. D. (2003). User acceptance of information technology: Toward a unified view. MIS Quarterly, 27(3), 425-478.

Vrasidas, C., \& McIssac, M. S. (1999). Factors influencing interaction in an online course. The American Journal of Distance Education, 13, 22-35.

Warschauer, M. (1997). Computer-mediated collaborative learning: Theory and practice. The Modern Language Journal 81 (4), 470-481.

Warschauer, M., \& Meskill, C. (2000). Technology and second language teaching and learning. In: Rosenthal, J. (Ed.), Handbook of Undergraduate Second Language Education. Lawrence Erlbaum, Mahwah, NJ. Yoon, K. (2004).

Wu, J. P., \& Chen, Y. H. (2006). The application of blog in case teaching-An exploratory study. Journal of Information Management--Concepts, Systems, and Applications, 8(2). URL (last checked 8 February 2012) http://jim.im.tku.edu.tw/8-2.htm/

Zeng, G., \& Takatsuka, S. (2009). Text-based peer-peer collaborative dialogue in a computer-mediated learning environment in the EFL context. System, 37, 434-446. 